AN ADDRESS V
CORROSIVE SUBLIMATE AS A SURGICAL DRESSING.

\author{
Delivered at the opening Mecting of the Mcdical Sacicty of London, \\ Monday, October 20 th, 18s4 \\ BY Sir JOSEPH LISTER, BART., F.R.S., \\ Professor of Clinical Surgery in King's College.
}

Mr. President and Gentlemes, - When, in an address delivered at the opening meeting of last session, I expressed myself in what some of my hearers regarded as terms of overweening confidence in tho trustworthiness of antiseptic treatment, I little thought that, a year later, I should have to tell you of failures on my own part; yet such is the casc. Several instances have occurred, within the last few weeks, of results deviating from our typical experience in antiseptic treatment, such as I was in no way prepared to meet with, and, in one case, a fatal event ensued. A lady, on whom I operated for scirrhus of the mamma, with removal of the axillary glands, died of a spurious pyæmia, or a variety of septicæmia, an occurrence such as $I$ have not met with for many years past. We dressed the wound in the nsual way. Two days after'the operation, there was pus already present at the anterior part of the incision. There happened to have been an umusual flow of blood at this part, where we do not, as a rule, expect much. It is a very unusual thing for pus to appear so carly. Wo used to say, in what I may term the pre-antiseptic days, that, if we operated upon sound tissues, suppuration occurred, provided primary union did not take place, in from three to four days, three days in children, four days in adults, and, perhaps, in warm weather, rather earlior than four days. For pus to occur to the amount of several drachms at the end of two days was, therefore, very nnusual, and some special form of organism, I have no doubt, was present. Micrococci vere, indeed, found after death in abscesses which had formed within the pleura. Nevertheless, though I believe some unusual organism was present, we have been accustomed to consider ourselves free from the apprehension of such ill effects; and, I am thankful to say, though no other fatal case occurred, there have been several instances of deviation from the typical course, where, in stead of union without suppuration at all, we have had healing retarded by the formation of more or less pus, undoubtedly of a septic character, in the sense in which we now use the term septic, that is to say, dependent upon the development of micro-organisms, although no smell was perceptible. Now, sir, I need hardly say that one such result as that to which I have referred, a fatal event under circumstances which we had been accustomed to consider absolutely free from danger, made me reflect most seriously; and the other cases, though less disastrous, were also grave cause for reflection.

In looking for the source of our misfortunes, it was to the external dressing that we naturally turned our attention. The experiences of Mr. Cheyne and Professor Ogston indicate pretty distinctly that the means which we ordinarily use are sufficient for the purpose of rendering our wounds free from mischievous micro-organisms at the time we put on our dressings. Both Mr. Cheyne and Professor Ogston have found, by using the most advanced mothods of investigation, that if a carbolic acid gauze dressing is changed daily, no organisms are met with in the discharges. That, I say, seems pretty conclusive evidence that the means which we have adopted hitherto for the purpose of keeping our wounds pure, up to the time when the dressings are applied, are sufficient. With regard to our external dressings, our suspicions tended to turn upon the eucalyptus gauze. Eucalyptus oil is undoubtedly a powerful antiseptic, and I have been using it in the form of gauze for a considerable time past. One difficulty with it is its great volatility. In the first instance I employed gum dammar, instead of common resin, in the manufacture of the gauze, because I found that gum dammar held the eucalyptus oil more securely than the resin does; but gum dammar is an expensive gum, and, after some trials with common resin, I thought I was justified in substituting the cheaper material, and for a while we seemed to get good results with this arrangement. But, as I have already said, more recently the results were not satisfactory. I mean that, now and again, a case occurred which was unsatisfactory. On making inquiry of the manufacturer of our eucalyptus gauze, i found that he had deviated from the instructions which he hal received as to the manufacture; that he often left the gauze, for a considerable time after it had been charged, exposed in the air before folding it up, thus affording opportunity for the escape of the volatile constituent in large amount; and in hot weather, such as.that during our reent summer, this was more especially apt to occur. We found, as a natter of fact, that the eucalyptus gauze supplied to us had not the soltness which. it ought to have, caused by the aclequate amannt of oucalyptus oil. I was thus led to attribute our disasters to imperfection in the manufacture of the eucalyptus gauze.

These circumstances led to a reconsideration of the subject, and to an appreciation afresh of the disadvantages of any volatile antiseptic substance. Volatile antiseptics have their own advantages, to which.I need not refer, but they have great disadvantages. In the first place, we are at the mercy of our manufacturer. The resin and parntinn so glue the folds of the gauze together, if it is allowed to cool in mass, that it must be opened up while warm, and upon the way in which this is done by the manufacturer much depends as to the quantity of the antiseptic present in the gauzc. In the next place, a volatile antiseptic, such as either carbolic acid or cucalyptus, has the disadvantage that it requires careful treatment by the surgeon himself. The material containing it must be kept in rell closed motallie vessels; otherwise evaporation soon impairs its qualities. And in the third place, there is this disadvantrge attending all volatile antiseptics, that tho longer the dressing is kept upon the body, the loss efficacious does it become; and who is to say when the time arrives when it has become so inefficacious that it is necessary to remove it? I lave been accustomed to regard a week as the limit of the time during which a carbolic acid gauze dressing may be regarded as effectual; but, beyond the fact that with this period our results wore on the whole satisfactory, we had not what we may call precise grounds to go upon. In that respect, a volatile anitisoptic must always be at a disadvantage, as compared mith a non-volatile one; which will be just as efficacious at the end of a month, or six weeks, as it is when first applied, provided it is not soaked with the discharge.

Salicylic acid is a non-volatile antiseptic; but salicylic acid, as I ascertained from experiments, sevcral years ago, is very far from being as powerful in antiseptic qualities as carbolic acid, and therefore $I$ have never ventured to use it for serious eases. Iodoform, while volatile, is rery slowly volatile, and, at the same time, so littlo soluble in the discharges, that in these points of view it seems an admirable antiseptic; but iodoform is by no means a potent agent in its action on micro-organisms. I ascertained, some years ngo, for example, that, taking a 10 per cent. iodoform wool, the strongest used, and soaking this with milk, the lactic fermentation was only a short time retarded, and in the course of a few dars, not only tho Bacterium lactis, but multitudes of other linds of bacteria were seen, in abundance, in the milk. Again, uncontaminated urine being made to soak such a piece of wool, and then inoculated with putrofying to soak such a picce of worloniacal formentation was ouly a short time retarded by the iodoform. Hence I was not surprised to learn that, in the practice of Schede of Hamburg, and others, it had been fis iodoform dressings. It is remarkable that iodoform has such an effect as it has in preventing putrefaction, but it is by no means a powerful germicide.

But there is another non-volatile antiseptic, corrosive sublimate, to which attention has been more esfrecially directed of late years by Dr. Koch; and here I may he permitted to give my tribute of praiso to the admirably conceived and conclusive experiments which he has performed upon this subject. Koch proceals in this sort of way ${ }^{1}$ : he dips a very small piece of silk thread into a fluid containing the spores of the bacillus anthracis, known to be highly resisting to the various agencies inimical to low organisms. After this silk thread has become dry, he dips it in the antisoptic solution to be tested, keeping it there for a minute, half a minute, five minutes, or any length of time that is required. He then, by means of water or alcohol, or some fluid known not to influence the vitality of the spores, washes away the antisentic from the threal, and bring into play his beautiful method of solid culture-material. He places the little bit of silk thread upon a piece of gelatine properly provided with nutritious material, and of course scrupulously pure, and observes, by means of the microscope, whether the spores in the silk thread develop or not. He ascertained, by experiments of this character, that a solution of only one part of corrosive sublimate in 20,000 parts of water was amply adequate absolutely to lestroy the

1 Vide Desinfection. Yon Dr. Robert Koch. Mittheilungm" d's K'niserlichen Gesundheits-Amtes, Band I. 1881 . 
vitality of the spores of the bacillus anthracis, about the most resisting spores that are known. But he found also that as weak a solution of the sublimate as one to 300,000 parts of a solution of extract of meat was sufficient to prevent the development of the spores so long as they remained in it; but when the silk thread, having been for any length of time in this exceedingly weak solution, was withdrawn from it, washed, and then placed upon the nutritious gelatine, development occurred as if the spores had not boen exposed at all to any injurious agency; and thus Koch established in a most definite manner the distinction, and a very important one it is, between two different effects of antiseptic acents-one, the action by which the vitality of organisms is destroyed; and the other, that by which development is simply arrested, or prevented temporarily from occurring, without the vitality of the spores being interfered with. The former we may term "germicidal action." For the latter, it is somewhat difficult to find a gool English term. I happened, I believe, to bo the first to use the rord "inhibitory" in English physiology, by the advice of my old friend, Dr. Sharpey, with reference to an early paper I was about to publish on what the Germans term the "Hemmungs Nerven-System ;" and as this same word Hemmung is used by the Germans for this checking or suspending action of antiseptics, without destruction of vitality, and as it is very important that we should have some term which distinguishes the one action from the other, 1 may venture to employ this same word "inhibitory"- a good old English word-for this action of antiseptics, and to speak of their " inhibitory action" as distinguished from their "germicidal action."

Now, these properties of corrosive sublimate were such as no other antiseptic agent had ever been ascertained to possess in anything like such dilute solutions. With regard to our purposes in antiseptic surgery, the inhibitory action of the antiseptic would be sufficient, pro. vided we be satisfied that our wound is left free from injurious organ. isms. and that the dressing which we apply, itself contains no such organisms still alive. Then, all we require is that the dressing should be able to prevent the de zelopment of organisms from without into the discharges with which the dressing may be soaked. That is obvious.

Corrosive sublimate has been used extensively already by our German brethren, chiefly in the form of sublimate wood-wool, as it is called, in which one half per cent. of corrosive sublimate, with an equal part of glycerine, is mixed with what is termed "wood-wool," namely, pinewood reduced almost to a state of powder by suitable niachinery. This is highly absorlent. It is employed in large masses, and, so used, has given many excellent results. At the same time, it is somewhat unwieldy in its application. Under certain circumstances, it is not convenient to have so large a mass as is essential for its safety, and wo have also varying reports as to its efficacy; and I may remark that we find some surgeons satisfied with what others would regard as a very mediocre kind of success with antiseptic treatment.

The circumstances te which I referred at the beginning of my ad. dress naturally made me turn my attention to corrosive sublimate; and I was desirous, if possible, to use it in a more concentrated form, so that it might be employed in a less bulky fashion. Accordingly, I prepared a gauze containing, instead of 1 per cent., 1 per cent. of the sublimate. The first case in which I used it was that of an clderly lady, from whom I romoved the namma and cleared out the axillary glands. I put immediately over the wound a piece of prepared oiled silk, which I dipped in a 1 to 500 solution of corrosive sublinate; then, over this, sublimate gauze, and outside all an abundant encalyptus dressing. On the following day, when we changed the dressing, I found that, under the oiled silk, exactly corresponding to its extent, the skin was highly irritated, and was covered with small vesicles. I also found that the inner side of the arm, where there was no wound, was in the same state of intense irritation. I covered the irritated parts of the inner side of the arm with cucalyptus gauzc, dipped in a weak solution of carbolic acid, and I applied to the wound the 1 percent. sublimate gauze without any intervening protective oiled silk. On the following day, I found that the little vesicular pustules, which had formed the firstdav underthe protective, had healed, and that the inner side of the arm also had recovered from itsirritation. How were these facts to be explained? I believe the explanation to be this. The 1 to 500 watery solution of corrosive sublimate, prevented by the oiled silk from escaping, had acted as a powerful irritant upon the skin; but when the 1 per cent. ganze was applied directly to the wound, the oozing of albuminous discharge from the pustules and from the edges of the wound, mitigated the action of the corrosive sublimate, and so prevented further irritation there. Again, in the case of the arm, what had occurred was, free perspiration had taken place, and the perspiration forming, with the "orrosive sublimate in the gauze, a watery solution, had produced irritation where the perspiration was, on the same principle as the watery' solution had caused irritation under the protective.
I continued to use a corrosive sublimate dressing in this case. It so happened that there was a very free hæmorrhage after the operation. I never before saw small vessels so atheromatous. We had to tio multitudes of little rigid arteries, and, in spite of this, a consider. able effusion of blood took place, and bagged under the skin. She left town with the outer angle of the wound still unhealed, and having the remains of the blood-clot exposed in it-the dressing employed being a piece of absorbent cotton-wool charged with about 5 per cent. of sublimate, secured in its place with collodion-and she came every few days to London to have the dressing changed. On these occasions I found that, although the serous discharge had soaked the wool more or less, there was no irritation caused by it; and the blood-clot, in course of time, presented an appearance which I never happen to have seen before. From the epidermic edges of the little wound, the epidermis crept over the surface of the blood-clot like the white claws of an animal, extending over the dark coagulum. We are familiar with the organisation of the coagulum in exposed wounds, and we are also familiar with the fact that in the course of time the superficial clot may be removed, and a scar found under it, without any suppuration having taken place, or any granulation, strictly speaking; but I never happened to have seen before this formation of epidermis extending over the surface of an exposed coagulum; and the explanation I believe to be that, while the sublimate wool rendered the wound, for surgical purposes, perfectly aseptic, the albuminous discharge from the wound prevented the sublimate from coming into operation as an irritant, and so we had, in a peculiarly perfect manner, complied with the essential conditions for the treatment of superficial sores-namely, the exclusion on the one hand of septic agency, and on the other of the irritating property of our dressing. I may add that the wound healed without a particle of pus having been formed from first to last.

While this case showed that in the sublimate we had an agent that might give very beautiful results, it also indicated that we were dealing with an edged tool, which, while it might do admirable work, was very apt also to cut our fingers; and the question suggested itself, Was it, after all, possible to use corrosive sublimate in such a way as to get the advantages without the disadvantages? The question, for instance, suggested itself, Suppose the discharge had been more considerable in this case, 80 as to sosk thoroughly through and through the dressings, what might then have been the result? What is the action of the albumen of serum or blood apon corrosive sublimate? How do they act upon each other? It is, I believe, a very general view in the profession, not to say among professed chemists, that albumen forms, with corrosive sublimate, an insoluble, or very sparingly soluble, albuminate; and that this albuminate is inert; whence the efficacy of white of egg as an antidote in corrosive sublimate poisoning. In the fourth edition of Miller's Chemistry, it is distinctly stated that an albuminate of mercury is formed as a precipitate when a solution of albumen is treated with corrosive sublimate. In the third appendix to Watts's Dictionary of Chemistry, the albuminates are still spoken of, and, in the intcrmediate appendices, there is nothing said to modify the view expressed in the original work, viz., "Mercuric albuminate is a white substance obtained by precipitating corrosive sublimate with albuminate of sodium (white of egg)." If it were really true that the albumen acting in a certain proportion on the corrosive sublimate would form with it an absolutely inactive compound, this would be a very serious consideration for the use of corrosive sublimate in surgical practice. The albuminous (proteid) constituents of the blood are enormously abundant; while the quantity of corrosive sublimate we can use in our dressings cannot be very great. According to the most recent views regarding albumen, its chemical equivalent is about six times that of corrosive sublimate; but the quantity of albuminous material in the serum of the blood is very much more than this in proportion to the sublimate we could think of employing. My first experiment upon this matter was as follows. I made a solution of albumen from white of egg, and then intro. duced it into some sublimate-wool, the quantity of albumen used being double that which would be requisite to neutralise the corrosive sublimate, according to the view to which I have referred. After leaving the albuminous fluid in the wool for a certain time, I squeezed the wool, and obtained a clear fluid, and I was surprised to find that this clear fluid tasted strongly of corrosivo sublimate-an albumonous fluid, containing twice the quantity of albumen that was essen. tial, according to the views to which I have referred, for neutralising the corrosive sublimate, had picked up from the wool corrosive sublimate enough to give the fluid that came out a strong taste of that substance. I mixed this liquid with an equal part of milk ob. tained from a dairy, and the milk remained perfectly free from souring, 
showing that the albuminous fluid which hal come through the wool had antiseptic qualities, as well as the taste of corrosive sublimate.

I afterwards made other experiments with blood itself and, that to which I will now refer, was with the serum of horse's blood. My first attempt to obtain serum from horse's blood failed. I wished to get the blood in an aseptic state, so far as one conveniently could without going too much into detail ; and I used a glass-jar which I had had by me for a long time past, and which had been used for experiments with regard to catgut, and had certain impurities adbering to it which could not be cleaned off. I purified this with a 1 to 500 solution of corrosive sublimate, and then introduced into a horse's jugular vein a glass tube purified in the same way, and through this tube drew blood into the jar, and allowed it to coagulate, intending to use the serum which should ooze out of the clot as it contracted. I was baffled, however, by finding myself again in presence of a fact which I described some years ago, where antiseptic precautions had been used in obtaining blood ; the clot never contracted.

When I. first witnessed this fact, having found the novel procedure of antiseptic precautions, in taking blood, followed by the novel phenomenon of failure of the clot tu contract, I was disposed to attribute the one to the other, and to imagine that the destruction of the septic organisms was, in some way or other, the cause of the absence of the shrinking. Then it was suggested to me that Liebig had shown, in his Letters on Chcmistry, that, if glasses are heated, they lose, for a time, their usual property of causing certain phenomena of crystallisation; and, as my glasses had been always purified by heat, there might be some peculiar physical property in the glass to account for the circumstance. But here we find the same phenomenon cropping up, although the glass had not beon purified by heat, and although it had not even a clean smooth surface.

It may be interesting to you to observe that, though the antiseptic precautions used were but of a rough kind, still no genuine putrefaction has occurred, in spite of the hot weather, in this blood taken on September 9th. But the remarkable fact to which I wish to direct your attention is that. while the huffy coat peculiar to horse's blood can still be recognised, it has entirely failed to contract, and is to be seen adhering to the surface of the ressel. I must confess it seems to me barely conccivable that the development of organisms can be the cause of the contraction of the clot under ordinary circumstances, considering how soon that contraction begins to come into play. Yet to what else are we to attribute it ? It is to me, I confess, a perfect mystery. At the same time, to us surgeons it must be admitted to be highly interesting, because in antiseptic surgery, at all events, this is the very condition of things in which we find the clot. Wo do not find a clot shrink away, or tend to do so, from the sides of the wound, but it retains its original bulk until it is gradually diminished by absorption and organisation; and if a clot forms in the vicinity of a ligature upon a large artery, it seems very important that it should not shrink away from the sides of the vessel, but remain there, in its original dimensions, to serve its purpose of a plug.

On the same occasion on which I obtained this blood. I received a portion in to another vessel, and stirred it during congulation to remove the fibrin. This whipped blood answered my purpose perfectly, because, by virtue of the remarkable tendency that the red corpuscles of the horse's blood have to aggregate into dense masses, and so fall rapidly in the course of a short time, the mixture of serum and red corpuscles was found, in three hours, to consist of abont one-half corpuscles and one-half serum, and therefore I could use the serum for the purpose of my experiment.

The experiment was perforined in the following manner. A glass tube, such as this (three-quarters of an inch in calibre and three inches in length), open at each end, was packed with a certain weight of antiseptic dressing to be tested, say sublimate wool, occupying about two inches of the tube; then a weighed quantity of serum, just enough to soak the wool, was poured in at one end of the tube held vertically; it was then left for about half-an-hour in a warm box at the temperature of the body, after being put into a stoppered bottle, to prevent evaporation; then the serum and the sublimate in the dressing having been allowed to act upon each other for about half an hour, a little more serum was poured in, the tube being in the same position as before. The result was that a certain quantity flowed out below, and was received into a test-tube. The lower part of the wool and the scrum in the test-tube were next inoculated with putrid blood, diluted with ten parts of water, to prevent the smell being so great as to make one think that putrefaction existed when none had occurred, a tenth of a minim being applied by means of a suitable apparatus. Lastly, the wool-tube in its stoppered bottle, and the test-tube with a cap of thin mackintosh tied orer its mouth, were replaced in the warm box. The object of this was, to ascertain whether the dressing, after having been thoroughly soaked through and through with serum, would resist a potent septic inoculation; and also whether the fluid that had come through the dressing was itself an antiseptic fluid. If such should prove to be the case, we should have all the requisites we could desire for an antiseptic dressing. It was a very severe test, for it is comparatively rarely that we have such intensely putrefying substances applied to the surface of our surgical dressings, and it is also comparatively rarely that the dressings are soaked so very thoroughly with blood or serum.

1 used three kinds of sublimate-wool, one containing 1 per cent.twice as much as there is in the wool-wool-one 5 per cent., and the other 10 per cent. I have mentioned that it was on the 9th of September that this was done, and all these three wools remain perfectly pure, so far as the scuso of smell can detect, to the present time. The bottles are before you, and even in that containing the 1 per cent. wool, you will find nothing but a smell, something between that of mortar and the inner bark of some trees, which is the immediate effect of the action of corrosive sublinate upon the serum. 'The scrum that had come through the dressing equally resisted the inoculation. By means of a process of testing with which I will not now trouble the society, I could ascertain pretty exactly the proportion of corrosive sublimate present in these liquids that had thus come through. The corrosive sublimate made the liquids turbid in the case of the wool with stronger proportions; but, in the case of the 1 per cent., it had not rendered the serum turbid, and therefore I was able, without the use of the microscope, to judge by the existing transparency, and also by the presence or alssence of scum on the surface, whether any organisms did or did not develop; and none whatever occurred. $\Delta$ s regards the strongest wool, the liquid which came through contained abont one part of corrosive sublimate to 160 parts of the fluid. I tasted this, and found it had the peculiar metallic nauseous taste of corrosive sublimate. I also mixed some of it with five parts of milk got from a dairy, and therefore, as we know, containing bacteria of various kinds. Here is the milk, still fluid after the lapse of nearly six weeks, although, when it was mixed with the serum, it was already advancing towards septic changes. 'The first of those changes, namely, lactic fermentation, has been prevented, otherwise the milk would not have been fluid, as you see it to be. There is not the slightest smell either of the lactic or butyric fermentation, but only that which Pasteur pointed out to occur as the result of oxidation of the fatty matter of milk-a little odour of suet. That is exactly the smell that you have in boiled milk kept for a few wceks in an aseptic state.

Thus, Mr. President, we had evidence that corrosive sublimate forms, with the serum of the blood, a material, whether we call it a chemical compound or not, which retains the properties of the corrosive sublimate, both as to taste and as to antiseptic virtue. Now it seems to me highly unlikely that both the characteristic taste of corrosive sublimate, and the antiseptic virtue, would be retained if the corrosive sublinate were decomposed in any way ; and, therefore, I venture to think, speaking with all deference to chemists, that we have not here a chemical combination in the ordinary sense, but an association of particles, such as occurs in solution : not an albuminate of mercury, but an albuminate of sublimate, if I may use such an expression; a loose association of particles of chloride of mercury with albumen. If such be the case, I need hardly point out how important this may be with reference to the surgical uses of corrosive sublimate. The discharges, in passing through a sublimate dressing, may acquire from that dressing chloricle of nercury, still in solution, though associated with: albumen, and still retaining antiscptic propertics.

I may conclude this matter of the relations of the blood-serum to corrosive sublimate by showing some illustrative specimens. I found that, if serum is mixed in small proportions with corrosive sublimate, in a mortar, the result is the production of a thick, oparque, slimy material; but if you ald a little more, and still a little more, you get this material redissolver in the serum, until, if you use as inuch as 150 parts of serum to one of sublinnate, you get a clear solution. This test-tube contains serum from the blood of a horse, mixed with one two-hundredth part of corrosive sublimate. You will see that there is no precipitate here at all. This other test-tube contuins the same anount of corrosive sublimate $(1$ to 200$)$; but the liquill mixed with it, instead of being serum simply, is serum with an equal part of distilled water ; and here we have what the ehemists describe as a precipitation of the albumen, the upper part of the liquid being clear. Now, this upper part of the liquid contains exceedingly littlc corrosive sublimate ; it has almost all gone down with the albumen; but if we take some of this precipitate itself and mix it with more serum, it will be redissolved by that serum. This afternoon, I nixed some 
of this precipitate with some serum already containing one fourhundreth part of sublimate, and the result has been the clear solution that you see here. This albuminate, if we are to call it so, is therefore highly soluble in blood-serum, and that is one imprortant point to which 1 wish to direct attention.

While the sublimate is thus, so to speak, intact when associated with albumen, it is rendered very much milder in its action. I took soune of the serum which had come through the 10 per cent. wool, containing one part of corrosive sublimate to 160 parts liquid, soaked a piece of lint with it, and applied it to my arm, put over this a piece of thin mackintosh cloth, to prevent evaporation, and secured this with rubler adhesive plaster. I retained this dressing in position for twenty-four hours, and on its removal found an absolute absence of any irritation, although my own skin is pretty sensitive. We have seen how, in tiventy-fuur liours, onc part of sublimate to 500 of water alrealy produced pustules; yet here one part to 160 of serum produced no irritation whatever. The association, then, of the albumen with the corrosive sublimate greatly mitigates its action, and makes it mnch less irritating. Thus we are able to understand how the dis. charges coming from a wound suaking a sublimate dressing may not cause irritation, although the dressing may contain a large proportion of corrosive sublinats. Such being the case, I hoped that we might be able to use corrosive sublimate in pretty strong proportions in a gauze for the dressing of wounds; and therefore, not very long ago, in a case of lisoas abscess, I applied gauze containing :) per cent. of corrosive sublimate, with a little gum Arabic to prevont the crystals flying off. On changing the dressing the follow. ing day, I sa! in the vicinity of the wound all perfectly satisfactory ; but, the divharge having gone principally backwards, I found that the further I looked towards the sacrum, the more and more evidence of irritation dial l tind, until over the sacrum itself, beyond the edgo of the dressin!, there was alsolutely a large vesicle. How was that to be expluined? The explanation I believe to be simply this. If an albuminons dischar pe travel; through a dressing containing corrosire sublimate only, it, in the first instance, forms, with the corrosive sublimate, a non-irritating alluminate, so to speak, but leaves more or loss of its allowmen behind in the form of a precipitate. As it goes further, and meets with more corrosire sublimate, it leaves more albumen behini, an! so, as it allvances, becomes more and more nearly is watery solution of corrosive sublimate, prolucing the highly irritating elfects with wl.ich we are familiar. This result, I confess, made me at tirst despair of using corrosire sublimate in anything like a concentrated form as a surgical dressing. But it afterwards occurred to me, might it not bo possible, as c.crosive sublimateassociated with albumen isso little irritating, to associate albumen with the corrosive sublimate in the dressing ? Whero shouli we get our allnmen from? Well, we may get it from horses' blood. 'There are in every town horse-slaughterers. If you stir horses' blood while it is coargulating, you may get from one animal some gallons in the form of serum. There is the albumen for you, if only it can lo made usefu!. There is a horse-slaughterer in the north of I.ondon who will let us havo this serum absolutely for nothing; it is simply a useless material to him. This bcing so, I iscertained in what proporticus the serum and the sublimate might be mixed, so as to give a worl:able article; and I find that you may omploy them in almost any proportions. If you use a very small amount of scrum, ron get, indeed, a thick opaque substance; but this ean be perfectly well blended with gauze or other materials. Here is a gauze which has becn charged with serum containing one part of corrosive sullimate to serenty-five. Two and a half parts of the liquid are reyuired for charging one part of the gauze; and you will see that this is not at :Il! an unpleasantly enstituted substance, physically. It is destitute of volour ; you will seareely perceive it to the taste; and you would hardiy believe that it contained nearly three parts per cent. of corrosive sublimate.

The corrosive siblimate is so intimately blended with the serum that, when it dries (as seen on this plate of glass), no separation of crystals take: place. Whether we use 1 to 100,1 to 70,1 to 50 , or even 1 to 30 parts of blood-serum, they are perfectly amalgamated, and therefore, from a gauze like that, no corrosive sublimate can fly ofl. It can be manipulated as you please, and, as applied dry to the skial, it is absolutely unirritating." Then, in the next place, it is unimitating as acted on by the perspiration. If water is made to act on sublimated serum dried, it does not redissolve it as serum does but it renders the mass opaque, the water being only partly absorbed into it ; and the water which remains unabsorbed contains exceedingly little of the corrosive sublimate, which is almost all retained by tho albumen. Hence, when perspiration soaks into such a dressing, though If such a gaure be turn, it gives of a dust which irritates the nostrils. It is.
therefore, better to cut it with selssors. it moistens it, it does not produce irritation. I made some gauze with serum 80 strong with corrosive sublimate as to have 1 part to 30 , which implies more than 6 per cent. of corrosire sublimate in the dried gauze. I moistenod a picce of this with distilled water, and fixed,it on my arm for six hours in the manner above described; and, when I removed it, I found the skin free from irritation. Thus, you will observe that, by associating albumen with the corrosive sublimate, we seem to be able to get rid of its irritating properties.

But the important question arises, Does corrosive sublimate, when thus associated with albumen, retain sufficient antiseptic virtue for surgical purposes? The method of experimenting which I have described is adapted for testing the efficacy of any antiseptic dressing, and $I$ have used it for various others besides sublimated ones. I have employed it for salicylic cotton-wool, for iodoform cotton-wool, for eucalyptus gauze, and for carbolic gauze. I have montioned that the test is an exceedingly severe one, and I find that, after the lapse of a few weeks, salicrlic wool soaked with serum and inoculated as above described, stinks; and the same is the case with iodoform wool. The eucalyptus gauze, however, if freshly prepared, remains pure; as also does carbolic gauze. Wo have scen that the 1 per cent. sublimate-wool resisted, still more the 5 per cent. and the 10 per cent. In accordance, therefore, with our previous experiments with iodoform and salicylic acid, they did not stand the test as well as carbolic acid, or eucalyptus, or the corrosive sublimate. But we get a different result if, instead of using serum of blood, we use scrum mixed with blood-corpuscles, such as we readily get from tho cow, in which the corpuscles do not aggregate so closely as in the horse, but remain suspended in the serum. I need not, of course, tell any members of this Society, that the corpuscles are enormously richer in proteid substances than the serum is, so that serum and corpuscles contain about 2 ? times as much of proteid material as the sorum does ; and as albuminous ma. terials mitigate the action of the corrosive sublimate, they cannot fail to interfere more or less, also, with its antiseptic action; and when we use serum and corpuscles, instead of serum only, we find that the sublimated wood-woof (which I should have said did very well with the serum so far as the sense of smell indicates) fails completely. The 1 per cent. sublimate-wool failed also; the 10 per cent., however, stood the test perfectly, cren with blood in substance. Now, as to our gauze made with albumen associated with the subiimate, the sero-sublimate gauze. Such a gauze, prepared with 1 part of sublimate to 100 of serum, stood the test absolutely when tried with serum. It therefore proved itself superior to salicylic and to iodoform wool. But with the blood in substance, how does it behave? The tube in this bottle contains a portion of the gauze treated with the cow's blood, serum and corpuscles, and inoculated nearly a month ago in the same potent manner to which I have referred, and you will observe that it has no putrid odour. Really, then, this sero-sublimate gauze seems to stand the test completely. I may say that, when tried with corpuscles and serum, our best eucalyptus gauze failed utterly, so that everything that I have tried failed with serum and corpuscles, except the strouger sublimate preparations and carbolic acid gauze.

Then the question comes, how far may we go in the strength of our sublimate combined with the albumen without causing irritation? During the last three weeks, my cases at the hospital have been dressed with this material. We have used the kind of gauze which was tested in the above experiments, made with 1 of sublimate to 100 of serum, and also one made with 1 of sublimato to 50 of serum. We find that the 1 to 50, in the majority of cases, has caused no irritation whatsoever, but in a very few it has caused some irritation, which, however, has disappeared, and the sores caused by the 1 to 50 have $h$ aled when the 1 to 100 has been substituted for it. Thereforeit ojks as if we were very near our limits, as if that prepared with 1 of sublimate to 100 of serum was trustworthy and unirritating, even to all skins, and that prepared with 1 to 50 was unirritating to most skins. Now there is this to be observed for our comfort, that the discharge both from wounds and from abscesses antiseptically treated is a serous discharge, not a bloody one, except in the case of wounds during the first twenty-four hours; and even in the first twenty-four hours, except in cases in which the dressing has to be taken down for reactionary hæmorrhage, the blood is always more or less diluted with serum. If, therefore, we hare a dressing which has stood our screre tost with serum mixed with the full amount of corpuscles, we are surely right in regarding it as trustworthy.

Last Friday, I amputated at the hip-joint in a boy 12 years of age, on account of a sarcoma of the lower half of the femur. The wound was exceedingly vascular, and there was a great deal of bloody oozing in the first twenty-four hours, but very little blood escaped externally, because this gauze absorbs very much better than our carbolic acid or cucalyptus gauzes do, containing as they do resin and paraffin ; and I 
would strongly recommend that, during the first twenty-four hours, this gauze should be used in at least sixteen layers. It is now three days since the operation was performed, and, from the perfectly normal temperature and returning appetite and strength, I think wo may be satisfied that the boy is already out of risk of septic complications. And this, you will observe, is a very testing case.

I may mention one other case, that of a boy six years old, from whom, nearly three weeks ago, I removed a portion of a rib, for the purpose of allowing free drainage to empyema. We let out thirty ounces of thick, odourless pus, and a great quantity came out afterwarls. He has been dressed with sero-sublimate gauze; and he is one of the instances in which gauze prepared with the 1 to 50 serum caused irritation, which disappeared under the 1 to 100 .

In him we have witnessed the beautiful course which, I believe, we can only see under antiseptic treatment efficiently managed, of no more pus formed after the first pus has been evacuated-nothing but a serous oozing rapidly diminishing; and I was delighted to see, on coming back after a fortnight's absence, how plump the emaciated little fellow had become. And the serous discharge is now so slight, that I believe it wonld be already safe to remove the drainage-tube. This case, I think, proves that our dressing is aseptic, that the germicidal properties of the corrosive sublimate have come into play in the preparation of the dressing, so that any injurious organisms which existed in the blood or in the gauze before they were brought into preparation, have been destroyed: because, if there had been merely the inhibitory influence of the sublimate upon the organisms, the serum pouring out from the pleura, washing away all the antiseptic in the vicinity of the wound, but leaving the organisms lodging among the fibres, then we should have had putrefaction, or other disturbing causes, showing themselves. No such thing having occurred, this case seems of itself sufficient evidence that our dressing is really a safe one in 80 far that it contains no living organisms of importance to start with.

I have here a sample of a very cheap fibre, sent me from the south of France, prepared with this sublimate-scrnm, and then teased out, showing that we may use this material for charging various fabrics. This fibre is highly absorbent; and I may remark that, if we have a very highly absorbent dressing, we may, and must, use a larger proportion of the sublimate. A gauze will absorb only about three times its weight of liquid; cotton-wool will absorb ten times its weight; and therefore you observe, when the one dressing is saturated, it has three times as much of the liquid in it, and thus has the sublimate three times as much diluted. Being so much diluted, it will be in proportion less irritating, but a stronger proportion is required to make it safe unless you use it in a very large mass. I belicve the French charpie, made of old rags, or even old rags themselves, might be quite well prepared with sublimated serum. I have here some rags which have been so treated, and which are quite absorbent, and therefore the dressing promises to be a very cheap one. If the serum is treated with a certain proportion of sublimate, not sufficient to make it solid, it may be kept for any length of time. For aught I know, this sublimated serum may come to be an article of commerce, which may be used in hospitals, or even in private practice. I also think it possible that a material of this kind, dried and reduced to powder, may come to be used for the purpose of mixing with vaseline for an antiseptic ointment, or even for dusting in, under certain circumstances, among our dressings.

I regret that time has not allowed me to bring this matter more completely to an issue as regards its practical applications. At the same time, though the subject is, to a certain extent, immature, I ventured to hope that the interest of some of the points to which I have referred, might justify me in bringing it before you.

\section{CASE OF ABNORMAL DEVELOPMENT OF A FOETUS}

\section{BY OLIVER WITHERS, L.R.C.P.Lond., M.R.C.S, Nottingham.}

Tne following case of fœtal malformation may not be without interest. I regret that circumstances would not allow a careful examination of the internal anatomy of the child, whose externa appearance at the time of birth I will try to describe. The child presentel by the breech, the malformation apparently offering no unusual impediment to delivery. On examination, after birth, I found the child twisted upon its vertical axis, as shown in the rough sketeh taken afterwards. The skin of the body was quite healthy in texture, showing that, although there was very marked post mortem rigidity of the body and limbs, yet the foetus could have been dead for only a very short period before birth.

On examination, the malformation was found to be limited to the npper limbs, the trunk, and the hend; the lower limbs were quite of the shape and size of those of a full-grown child at the time of birth The head was most remarkable in appearance, tho month being wide open with complete eversion of the upper lip, beneath which was the flattened and everted alveolus covered with normal gum-tissue. Lying upon the floor of the mouth was the small, thongh perfectly formed tongue, with the fauces and urula above. The skull felt soft and membranous, and there were mere slits in the facial part of it, corresponding to the right ear and nose; the right eye scemed to bo entirely wanting, and its place taken $u p$ by a slit similar in appearance to the one belonging to the left ear, though there was no pinna to be found upon the right side. There was complete fusion of the head and thorax. No alnormality could be found in the left upper limb in its upper part,

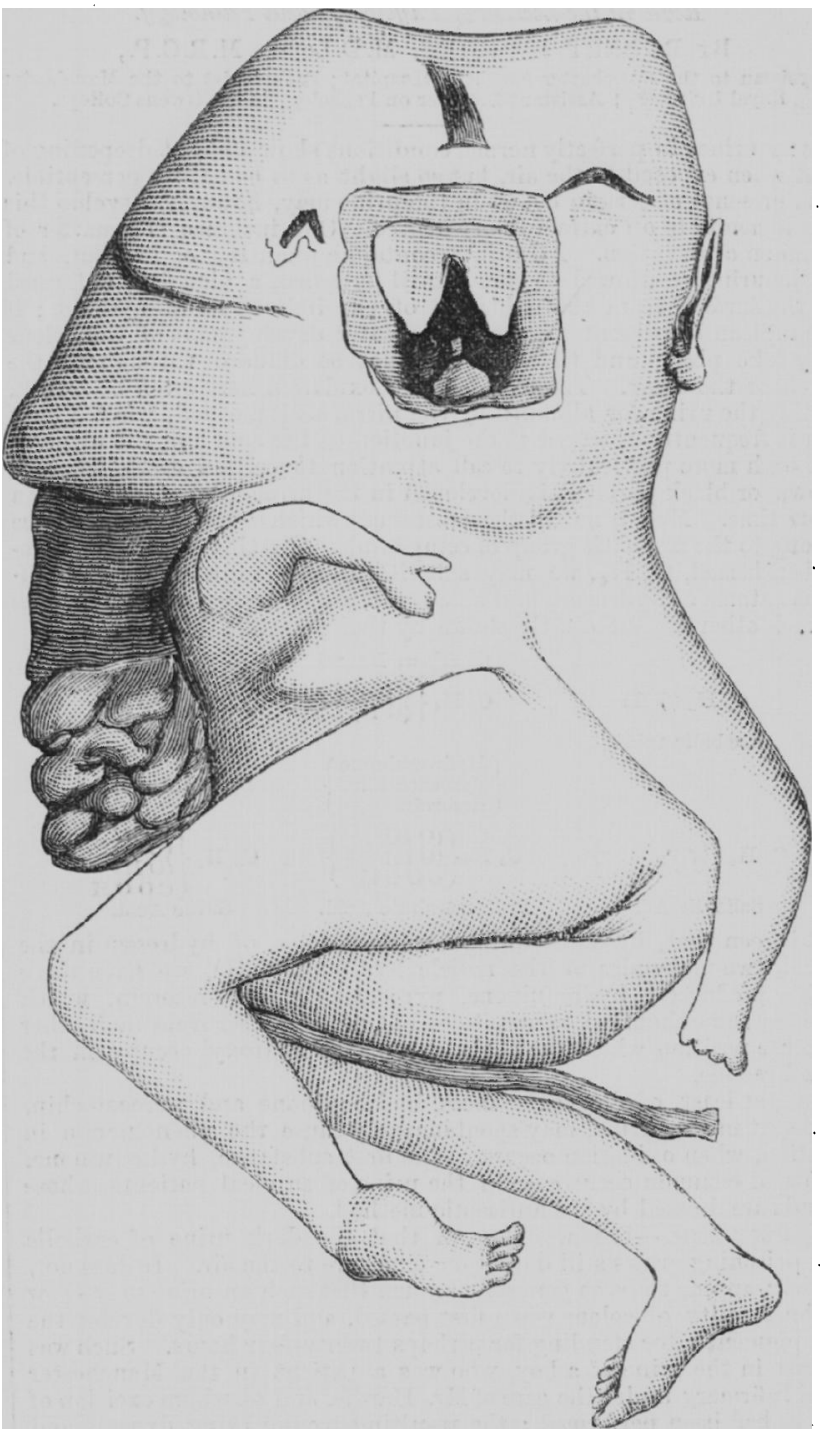

though the hand and wrist were nunaturally small, and the thumb and fingers were represented by five short knobby protuberances, with incomplete divisions between them. On the other hand, the right upper limb was quite rudimentary, as seen in the figure. The abdominal viscera were external to the boly, and the peritoneal cavity communicated with the outside by a cleft about two inches wille in tho anterior body-wall, through which the visccra protruded. Not the least abnormality could be discorered in the lower limbs, though tho left foot was twisted, owing to the position of the child in utero. A sinilar ectropic form of monstrosity has been described by Vrolik, and is mentioned in Leishman's Midwijcry. It may be mentioned that tho mother has had two other children perfectly free from any deformity. The placenta and cord were of the ordinary type 